\title{
Moleküler Baskılanmış Polimer Temelli Kreatinin-Seçici Katı-Hal Mikrosensör
}

\author{
Nurşen DERE ${ }^{1}$, Zuhal YOLCU², Murat YOLCU ${ }^{3 *}$
}

\section{$\ddot{\mathbf{O z}}$}

Kreatinin baskılanmış polimer temelli bütünüyle katı-hal polivinilklorür (PVC)-membran potansiyometrik kreatininseçici mikrosensör geliştirildi. Baskılanmış polimer sentezinde; kalıp molekül, fonksiyonel monomer ve çapraz bağlayıcı olarak sırasıyla; kreatinin, metakrilik asit ve etilen glikol dimetakrilat (EGDMA) kullanıldı. Elde edilen kreatininbaskılanmış polimerin iyonofor olarak kullanılmasıyla, PVC-membran yapısında kreatinine karşı seçici bir yanıt elde edildi. Kreatinin-seçici mikrosensörün bazı potansiyometrik performans özellikleri (doğrusal çalışma aralığı, tayin sınırı, seçicilik, eğim, cevap süresi, kullanım ömrü, $\mathrm{pH}$ ve sıcaklık vb.) incelendi. Hazırlanan mikrosensör, $57,2 \pm 1,2 \mathrm{mV}\left(\mathrm{R}^{2}\right.$ : 0,9979) eğimle $10^{-1}-10^{-5}$ mol.L ${ }^{-1}$ konsantrasyon aralığında Nernst davranışı sergiledi. Geliştirilen mikrosensör elde edilen potansiyellerde önemli farklılıklar olmaksızın yaklaşık olarak altı hafta boyunca kullanıldı. Geliştirilen mikrosensörün

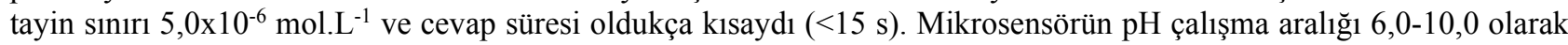
belirlendi. Geliştirilen mikrosensör kullanılarak, sentetik numunelerde bulunan kreatinin başarıyla tayin edildi. Elde edilen potansiyometrik veriler, UV spektroskopi yöntemi ile elde edilen verilerle karşılaştırıldı ve metotların \%95 güven sevisinde uyumlu olduğu sonucuna varıldı.

Anahtar Kelimeler: Kreatinin, Mikrosensör, Moleküler baskılanmış polimer, Potansiyometri, PVC-membran.

\section{Creatinine-Selective Solid-State Microsensor Based on Molecular Imprinted Polymer}

\begin{abstract}
A solid-state polyvinylchloride (PVC)-membrane potentiometric creatinine-selective microsensor based on a creatinineimprinted polymer was developed. For the imprinted polymer synthesis process; creatinine, methacrylic acid and ethylene glycol dimethacrylate (EGDMA) were used as template molecule, functional monomer and crosslinker, respectively. By using the obtained creatinine-imprinted polymer as an ionophore, a selective response was obtained towards creatinine in the PVC-membrane structure. The potentiometric performance characteristics (linear operating range, detection limit, selectivity, slope, response time, lifetime, $\mathrm{pH}$ and temperature, etc.) of the creatinine-selective microsensor were investigated. The prepared microsensor exhibited Nernst behavior in the concentration range of $10^{-1}-10^{-5}$ mol. $\mathrm{L}^{-1}$ with a slope of $57.2 \pm 1.2 \mathrm{mV}\left(\mathrm{R}^{2}: 0.9979\right)$. The developed microsensor was used for approximately six weeks without significant differences in the potentials optained for creatinine. The detection limit of the developed microsensor was 5.0x $10^{-6} \mathrm{~mol}$. $\mathrm{L}^{-1}$ and the response time was rather short $(<15 \mathrm{~s})$. The $\mathrm{pH}$ working range of the microsensor was determined as 6.0-10.0. Using the developed microsensor, the creatinine determination was successfully performed in synthetic samples. The obtained potentiometric data were compared with the results obtained by UV spectroscopy method. The obtained results were in good harmony in $95 \%$ confidence level.
\end{abstract}

Keywords: Creatinine, Microsensor, Molecular imprinted polymer, Potentiometry, PVC-membrane.

\footnotetext{
${ }^{1}$ GiresunÜniversitesi, Bilimleri Enstitüsü, Kimya ABD Doktora Öğrencisi, Giresun, Türkiye, nursen.dere@giresun.edu.tr

${ }^{2,3}$ GiresunÜniversitesi, Fen-Edebiyat Fakültesi, Kimya Bölümü, Giresun, Türkiye, zuhal.yolcu@giresun.edu.tr murat.yolcu@giresun.edu.tr
}

${ }^{1}$ https://orcid.org/0000-0001-7964-7445 ${ }^{2}$ https://orcid.org/0000-0001-7761-122X ${ }^{3}$ https://orcid.org/0000-0003-3477-3792 


\section{Giriş}

Kreatinin (Şekil 1), vücuttan kreatin parçalanması sonucu salınan bir metabolik atık üründür (Horne ve Swearingen, 1993). Kreatinin, kreatin yan ürünü olarak kendiliğinden ve enzimatik olmayan bir bozunma sonucu oluşan bir moleküldür (Wyss ve Kaddurah-Daouk, 2000). Günlük kas yıpranması sırasında ortaya çıkan kreatinin seviyeleri, kas-böbrek fonksiyonunun hesaplanmasında önemli rol oynar. Kadın serumundaki normal kreatinin aralığı 5-11 ppm iken erkeklerde 6-12 ppm'dir (Davis, 2021). Kreatinin konsantrasyonu 15,836 ppm'in üzerine çıktığında tıbbi müdahale gerekirken, 59,952 ppm’i aştığında ise böbrek hastalığının göstergesidir. Ayrıca; böbrek yetmezliğinde kreatinin konsantrasyonu 113,18 ppm'in üzerine çıkabilir. Bunlara ek olarak; böbrek hastalığı olan kişilerde kreatinin miktarınının günlük olarak kontrol edilmesi gerekmektedir (Kintzel, 2001). Normal kreatinin seviyesinin korunması önemlidir, çünkü yüksek seviyedeki kreatinin diyabetik nefropati, eklampsi, glomerülonefrit, kas distrofisi, preeklampsi, piyelonefrit azalmış renal kan akışı, böbrek yetmezliği, idrar yolu tıkanıklığı ve üretritin gibi rahatsızlıkların göstergesidir. Bunlara ilaveten; koyu renkli idrar, idrara çıkmanın aciliyeti, hematüri, yorgunluk, ayaklarda veya ayak bileklerinde kas şişmesi, halsizlik, kusma veya mide bulantısı, kafa karışıklı̆̆ı, nöbet gibi belirtilerde görülebilir. Düşük seviyedeki kreatinin ise müsküler distrofi ve miyasteninin göstergesi olabilir (Delaney ve ark., 2002).

Biyolojik numunelerde kreatinin miktarının belirlenmesi için yüksek performanslı sıvı kromatografisi (Carducci ve ark. 2002), gaz kromatografisi (Tsikas, 2010), s1vı kromatografi-tandem kütle spektrometrisi (Sukhang, 2020), kızılötesi spektroskopi (Barnea ve Abookasis, 2019), kapiler bölge elektroforezi (Vitali ve ark., 2017) ve UV/Vis spektrofotometri (Mohammadi ve Khayatian, 2015) gibi farklı analitik yöntemler kullanılmaktadır. Bu yöntemler hem karmaşık numune hazırlama prosedürü hem de pahalı ekipman gerektirdiği için zaman alıcıdır. Öte yandan elektrokimyasal yöntemler, analitin belirlenmesini düşük maliyetle kolaylaştırır ve iyileştirir. İyon-seçici elektrotlar daha pahalı yöntemlerle karşılaştırıldığında; düşük tasarım maliyeti, düşük tayin limiti, geniş çalışma aralığı, kısa cevap süresi, yüksek seçicilik, minimum numune hazırlama süresi, doğruluk ve hassasiyet, basit tasarım ve basit ölçüm gibi çeşitli avantajlara sahiptir (Işıldak ve Covington, 1993).

Moleküler baskılanmış polimerler (MBP), hedef molekül için mükemmel seçicilik gösteren yüksek oranda çapraz bağlayıcı kullanılarak oluşan katı maddelerdir. Moleküler baskılama yöntemi; hedef molekülün, monomer ve çapraz bağlayıcı ile birlikte polimerize edilmesi işlemidir (Sellergren ve ark., 2001; Kryscio ve Peppas, 2012; Cheong ve ark., 2013) ve hedef molekül için spesifik tanıma ve bağlanma bölgeleri oluşturduğu için önemli bir tekniktir (Chen ve ark., 2011). Polimerizasyondan sonra hedef molekül uygun bir çözücü yardımı ile polimer yapısından uzaklaştırılır ve böylece polimer yapısında hedef moleküle özgü bir kavite oluşur. Bu teknik, moleküler tanıma boşluklarına 
sahip bir polimer matris oluşturmak için hızlı ve çok uygun bir yöntemdir. Sonuç olarak; MBP'ler şekil, boyut ve işlevsellik açısından hedef moleküle özgü yüksek seçiciliğe sahip özel bağlanma bölgeleri sağlar. MBP’lerin iyi fiziksel ve kimyasal kararlılık, yüksek seçicilik ve düşük maliyet gibi birçok avantajları vardır. MBP’ler; ilaç salınımı (Hu ve ark., 2019), katı faz ekstraksiyonu (Ge ve ark., 2010), enzim simulasyonu (Salgarello, 2013), kromatografik ayırma (Borisov ve ark., 2019), kanser biyobelirteçleri (Wanga ve ark., 2010) ve sensörlerde (Yolcu ve Dere, 2018) yaygın olarak kullanılmaktadır.

$\mathrm{Bu}$ çalışmada, kreatinin-baskılanmış polimerin (KR-BP) iyonofor olarak kullanılmasıyla bütünüyle kat1-hal PVC-membran potansiyometrik kreatinin-seçici mikrosensör tasarlandı. Hazırlanan mikrosensörün potansiyometrik davranışları (tayin sınırı, seçicilik, doğrusal aralık, eğim, cevap süresi, sıcaklık ve pH aralığı vb.) ayrıntılı olarak incelendi. Hazırlanan mikrosensör kullanılarak, sentetik numunelerdeki kreatininin potansiyometrik tayini başarıyla gerçekleştirildi. Elde edilen sonuçlar UV spektroskopi yöntemi ile \% 95 güven seviyesinde karşılaştırıldı.

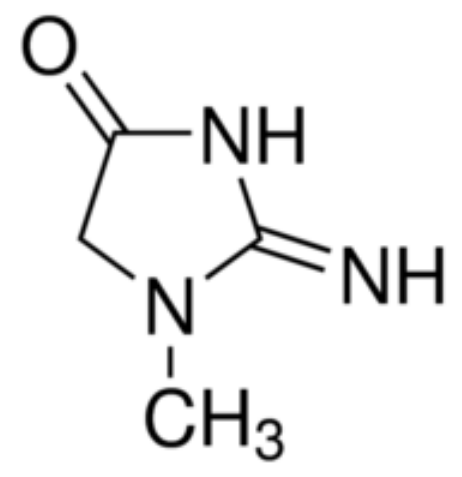

Şekil 1. Kreatinin (2-amino-1-metil-2-imidazolin-4-on) molekülünün yapıs1.

\section{Materyal ve Metot}

\subsection{Kimyasallar}

Metakrilikasit (MMA), kreatinin, azobisizobütironitril (AİBN), etilen glikol dimetakrilat (EGDMA), asetonitril, etanol, yüksek molekül ağırlıklı polivinilklorür (PVC), tetrahidrofuran (THF), o-nitrofeniloktileter (o-NFOE), dioktilsebakat (DOS), dibutilsebakat (DBS), potasyumtetrakis(pkloro)fenilborat (KTpClPB) ve grafit Sigma Aldrich (Bucks, Switzerland) firmasından, epoksi reçinesi (Ultrapur SU 2227) Victor (Italy) firmasından, sertleştirici (Desmodur RFE ) Bayer AG (Germany) firmasından, çalışmada kullanılan diğer tuzlar ve çözücüler Merck (Darmstadt, Germany) firmasından sağlandi. 


\subsection{Cihazlar}

Potansiyel ölçümleri, tasarımı ve yazılımı araştırma laboratuarımızda geliştirilen ve bilgisayar programı ile desteklenmiş çok kanallı potansiyometre cihazıyla gerçekleştirildi. Potansiyel ölçümlerinde referans elektrot olarak, $\mathrm{Ag} / \mathrm{AgCl}$ referans elektrotu (Basi-MF-2079-RE-5B) kullanıldı. Çözeltilerin hazırlanmasında kullanılan ultra saf su Sartorius Stedim (Arium*611UV) marka ultra saf su (18.6 M $\Omega$ ) cihazı kullanılarak temin edildi. Polimerden kreatininin çıkarılması için bir Memmer (GmbH \& Co. KG D.91126 Tip: WNB 14) çalkalayıcı kullanıldı. Tartım işlemlerinde Shimadzu (model AUX220) marka analitik terazi kullanılmıştır. Santrifüj için Kubota (model 4200) marka santrifüj kullanıldı. Yüzey görüntüleri için A Jeol JSM-6610 serisi bir taramalı elektron mikroskobu (SEM) cihazı kullanıldı. Son olarak, kreatinin ölçümlerinin spektroskopik tayininde Thermo Scientific Evuluation Array UV-Vis Spektrofotometre kullanıldı.

\subsection{Kreatinin-Baskılanmış Polimer Sentezi}

Kreatinin-baskılanmış polimerin hazırlanma süreci Şekil 2'de şematik olarak gösterilmiştir. Literatürde atrazin molekülünün baskılanması amacıyla önerilen sentez metoduna (Royani ve ark., 2014) benzer bir metot uygulanarak kreatinin-baskılanmış polimer sentezlendi. 50 mL'lik bir cam balon içerisine alınan 6,2 mL asetonitrilde $59 \mathrm{mg}$ kreatinin, 0,4 mL MMA ve 1,24 mL EGDMA çözüldü. Çözeltiden 15 dakika saf azot gazı geçirildi, su banyosunda 20 dakika sonike edildi ve sonra karışıma 0,02 mg AİBN ilave edildi. Çözelti, bir manyetik karıştırıcı üzerinde termostatik olarak ayarlanmış bir yağ banyosunda $60{ }^{\circ} \mathrm{C}$ 'ye kadar 1 sıtıldı ve 24 saat sonunda polimerizasyon işlemi tamamlandı. Renksiz yarı saydam bir katı polimer kütlesi elde edildi. Elde edilen bu polimer yapısında kreatinin bulunduğu için kreatinin içeren polimer (KR-İP) olarak adlandırıldı. Elde edilen polimer partikülleri süzüldü ve etanol ile y1kand. Metanol/asetikasit $(90 / 10 ; \mathrm{h} / \mathrm{h})$ çözeltisi, filtrelenmiş çözeltide UV spektrofotometri yöntemi ile herhangi bir kreatinin tespit edilmeyene kadar polimerden kreatinin moleküllerinin uzaklaştırılması için tekrar tekrar kullanıldı. Son ürün olarak elde edilen polimer tozu $50{ }^{\circ} \mathrm{C}$ 'de vakum altında kurutuldu ve kreatinin baskılanmış polimer (KRBP) olarak adlandırıldı. Kreatinin kullanılmadan aynı prosedür izlenerek baskılanmamış polimer olarak adlandırılan polimer tozu da sentezlendi ve karşılaştırma amacıyla iyonofor olarak kullanıldı.

\subsection{Kreatinin seçici mikrosensör üretimi}

Hazırlanan tümüyle katı-hal kreatinin seçici mikrosensör, önceki çalışmamızda açıklanan yönteme göre üretildi (Işıldak ve ark., 2004). Sensör üretiminin ilk aşamasında; \% 50 grafit, \% 35 
epoksi ve \% 15 sertleştirici THF içerisinde homojenize edildi. İkinci aşamada; yaklaşık $10 \mathrm{~mm}$ uzunluğunda ve $2 \mathrm{~mm}$ yarıçapında dış yüzeyi yalıtılmış bir bakır tel, yaklaşık 0,5 mm kalınlık elde edilene kadar bu karışıma birkaç kez daldırıldı ve laboratuvar koşullarında bir gün kurumaya bırakıldı. Son aşamada; PVC-membran kokteyl karışımına (4-6 (a/a) KR-BP, \% 67-69 (a/a) o-NFOE, DOS veya DBS, \% 26-27 (a/a) PVC ve \% 1 (a/a) KTpCIPB 2,5 mL THF içerisinde) ikinci aşamada oluşan katı temas yüzey 4-5 kez daldırıldı ve hazırlanan mikrosensör bir gün laboratuvar şartlarında kurumaya bırakıld1. Mikrosensör bu son haliyle potansiyometrik performans özelliklerinin incelenmesi amaciyla kullanıldı.
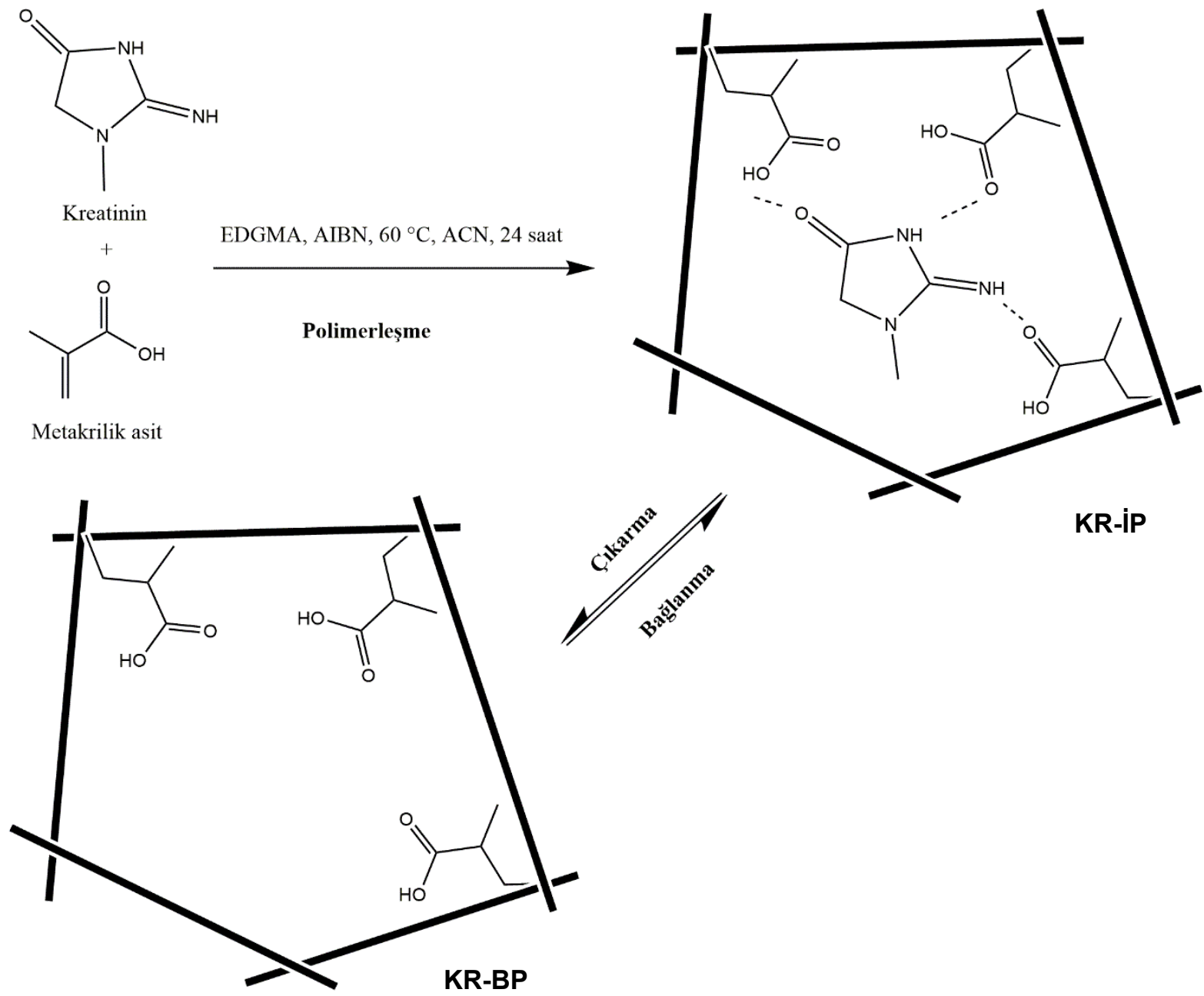

KR-IP

Şekil 2. KR-BP sentez sürecinin şematik gösterimi.

\section{Bulgular ve Tartışma}

\subsection{SEM Analizi}

KR-İP, KR-BP ve baskılanmamış polimerin yüzey morfolojileri SEM analizi yoluyla incelendi. İlgili SEM mikrografikleri Şekil 3'te görülmektedir. Mikrografikler incelendiğinde, polimer 
parçacıklarının yapısal farklılıklara sahip olduğu söylenebilir. KR-İP (Şekil 3a-b) ve KR-BP (Şekil 3c-d) tanecikleri baskılanmamış polimer taneciklerine (Şekil 3e) kıyasla daha küçük boyuttadır. Baskılanmamış polimer parçacıklarının, diğerlerine kıyasla daha homojen olduğu ve ayrıca genel görüntüsünün KR-IPP taneciklerine benzediği söylenebilir. KR-BP yüzeyinin (Şekil 3d) KR-İP yüzeyine (Şekil 3b) kıyasla daha geniş bir yüzey alanına ve daha gözenekli bir yapıya sahip olduğu gözlemlendi. Bu durum baskılama işleminin etkisini kısmen desteklemektedir. Sonuç olarak, KRBP'nin nispeten daha gözenekli yüzeyi, kreatinin için uygun etkileşim bölgelerine ve özel boşluklara sahiptir. Bu durum potansiyometrik bulgularla da desteklenmiştir.
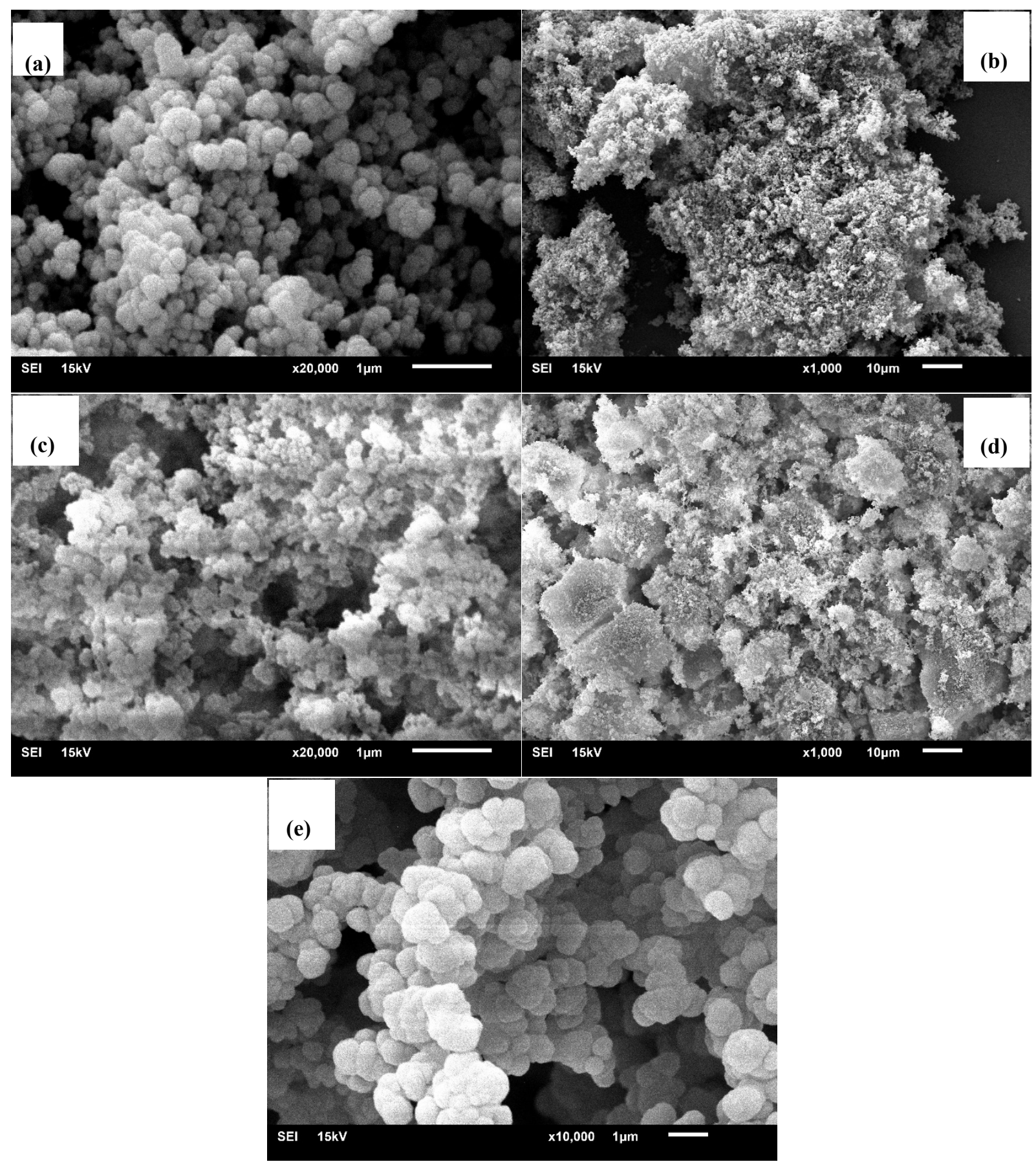

Şekil 3. KR-İP (a, b), KR-BP (c, d), ve baskılanmamış (e) polimerlerin SEM görüntüleri. 


\subsection{Optimum Membran Bileşiminin Belirlenmesi}

Kimyasal sensörler için ideal membran oranlarının belirlenmesi önemlidir. Çünkü membranın içerdiği türler ve miktarları sensör performansını oldukça etkilemektedir. Bu nedenle çalışmamızda çok sayıda ve farklı membran bileşimine sahip sensörler hazırlanarak test edildi ve en iyi performansı sergileyen sensör belirlendi. İncelenen membran bileşimleri ve bazı potansiyometrik performans özellikleri Tablo 1'de verilmiştir.

Tablo 1. İncelenen membran bileşimleri.

\begin{tabular}{|c|c|c|c|c|c|c|c|c|c|}
\hline \multirow[b]{2}{*}{ No } & \multicolumn{6}{|c|}{ Membran Bileşimi (\% a/a) } & \multicolumn{3}{|c|}{ Potansiyometrik Özellikler } \\
\hline & PVC & o-NPOE & DOS & DBS & KTpClPB & KR-BP & $\begin{array}{l}\text { Eğim } \\
\text { (mV) }\end{array}$ & $\begin{array}{l}\text { Doğrusal aralık } \\
\left(\mathrm{mol}^{\left.-L^{-1}\right)}\right.\end{array}$ & $\begin{array}{l}\text { Tayin limiti } \\
\left(\text { mol.L }^{-1}\right)\end{array}$ \\
\hline I & 26 & 69 & - & - & 1 & 4 & 49,1 & $10^{-1}-10^{-5}$ & $7,1 \times 10^{-6}$ \\
\hline II & 26 & - & 69 & - & 1 & 4 & 57,2 & $10^{-1}-10^{-5}$ & $5,0 \times 10^{-6}$ \\
\hline III & 26 & - & - & 69 & 1 & 4 & 43,7 & $10^{-1}-2 \times 10^{-5}$ & $8,1 \times 10^{-6}$ \\
\hline IV & 27 & 69 & - & - & - & 4 & 39,3 & $10^{-1}-10^{-5}$ & $7,3 \times 10^{-6}$ \\
\hline $\mathrm{V}$ & 27 & - & 69 & - & - & 4 & 50,5 & $10^{-1}-10^{-5}$ & $6,1 \times 10^{-6}$ \\
\hline VI & 27 & - & - & 69 & - & 4 & 41,6 & $10^{-1}-5 \times 10^{-5}$ & $9,6 \times 10^{-6}$ \\
\hline VII & 26 & 67 & - & - & 1 & 6 & 45,8 & $10^{-1}-10^{-5}$ & $7,0 \times 10^{-6}$ \\
\hline VIII & 26 & - & 67 & - & 1 & 6 & 52,6 & $10^{-1}-10^{-5}$ & $6,5 \times 10^{-6}$ \\
\hline IX & 26 & - & - & 67 & 1 & 6 & 42,2 & $10^{-1}-3 \times 10^{-5}$ & $8,3 \times 10^{-6}$ \\
\hline
\end{tabular}

Tablo 1 incelendiğinde; özellikle eğim ve tayin limiti açısından II nolu olarak tanımlanan sensörün en iyi performansı sergilediği görülmektedir. Çalışmanın devamında II nolu sensörün potansiyometrik performans özellikleri daha ayrıntılı olarak incelenmiş ve elde edilen sonuçlar sırasıyla aşağıda özetlenmiştir. Şekil 4 'te $1 \times 10^{-7}-1 \times 10^{-1}$ mol.L ${ }^{-1}$ derişim aralığındaki standart kreatinin çözeltilerine sırasıyla daldırılan KR-seçici mikrosensörün potansiyometrik davranışı ve bu sensöre ait kalibrasyon grafiği (sağ üstte) birlikte görülmektedir.

Grafikler incelendiğinde; sensörün geniş bir derişim aralığında $\left(1 \times 10^{-5}-1 \times 10^{-1}\right.$ mol.L $\left.\mathrm{L}^{-1}\right)$ doğrusal davrandığı, kısa cevap zamanına $(<15 \mathrm{~s})$ sahip olduğu görülmektedir. Sensörün tayin sınırı

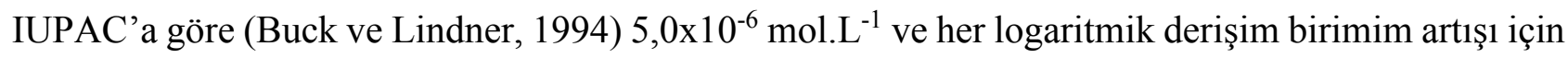

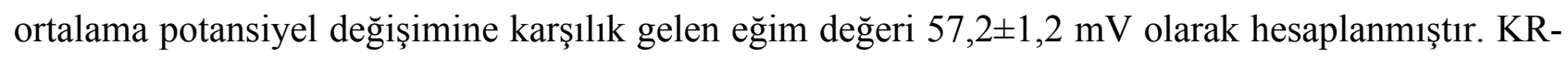
BP ve baskılanmamış polimer içeren membranlar ile hazırlanan sensörlere ait kalibrasyon grafikleri karşılaştırmalı olarak Şekil 5'te verilmiştir. KR-BP kullanılarak hazırlanan (MBP tabanlı) sensörün potansiyometrik performansı, baskılanmamış polimer tabanlı sensöre kıyasla belirgin şekilde daha üstündür. Açıkçası, baskılanmamış polimer tabanlı sensörün yanıtı, polimer taneciklerinin yüzeyindeki spesifik olmayan etkileşime atfedilebilir. 


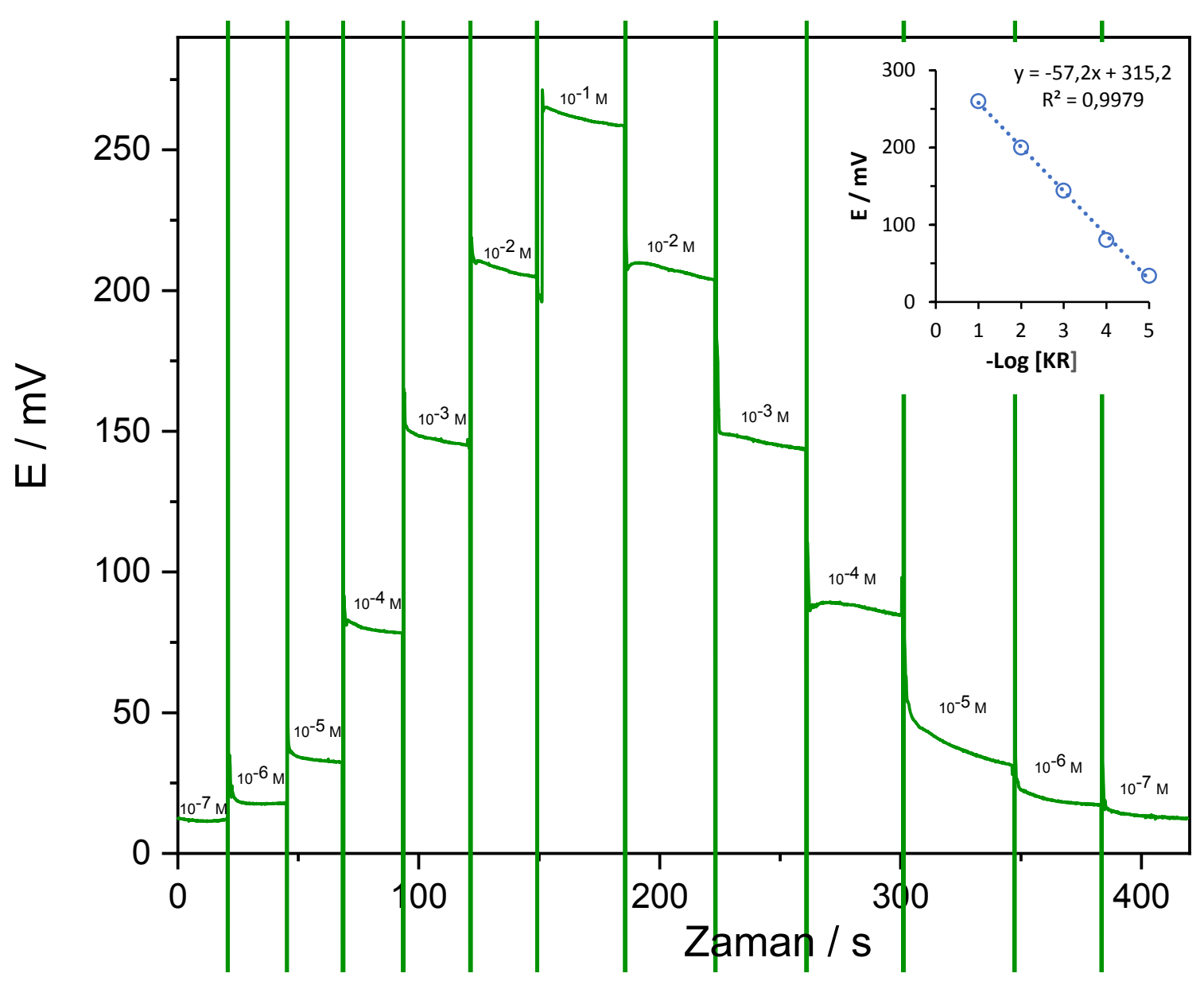

Şekil 4. KR-seçici mikrosensöre ait potansiyel-zaman grafiği.

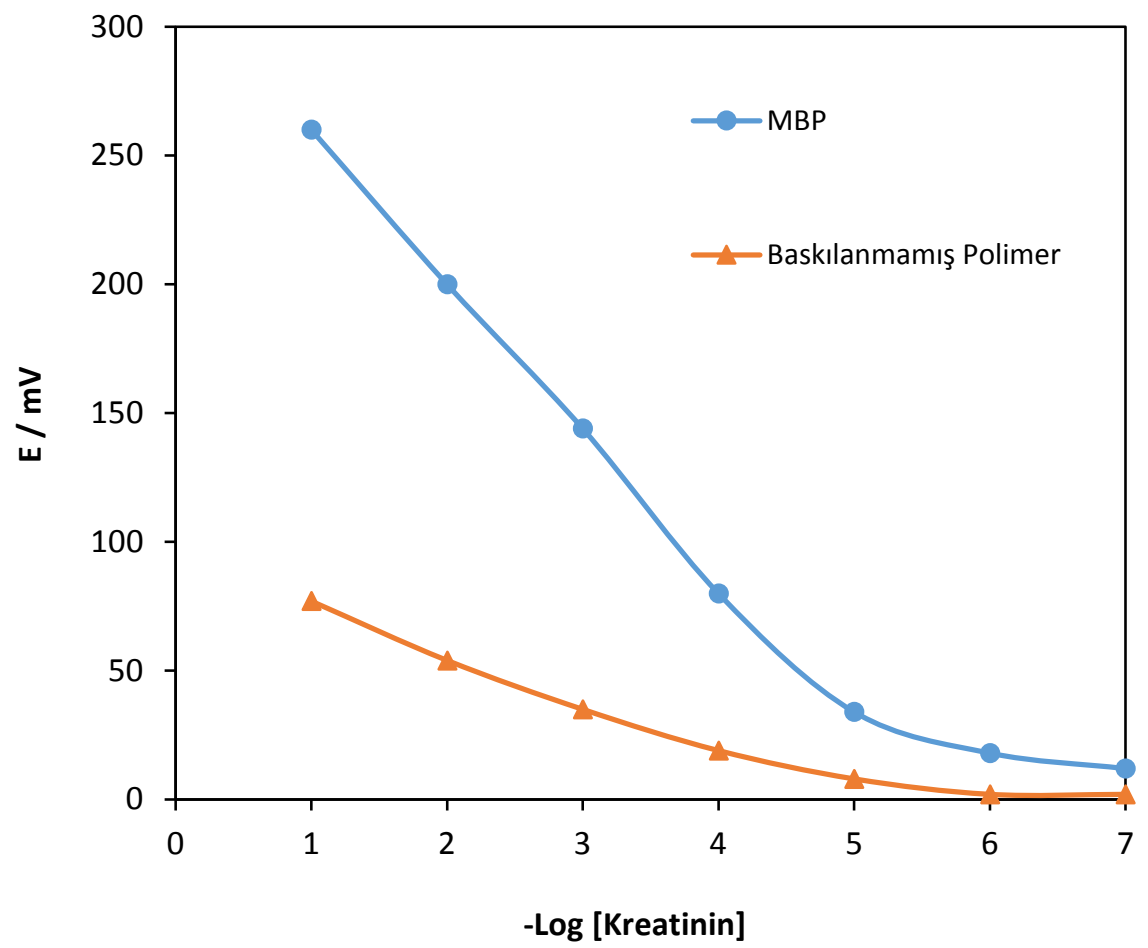

Şekil 5. MBP ve baskılanmamış polimer tabanlı sensörlere ait kalibrasyon grafikleri. 


\subsection{Tekrarlanabilirlik ve Yaşam Ömrü}

Geliştirilen sensörün tekrarlanabilirliğini incelemek amacıyla; KR-seçici mikrosensör standart kreatinin çözeltilerine sırasıyla 5'er kez daldırılmış ve tekrarlanan potansiyometrik ölçümler alınmıştır (Şekil 6.). KR-seçici sensöre ait tekrarlanabilirlik ölçümleri için potansiyel değerleri, ortalama ve standart sapmaları ile birlikte Tablo 2'de verilmiştir. Sensörün sergilediği davranışın oldukça düşük standart sapma ile tekrarlanabilir olduğu söylenebilir.

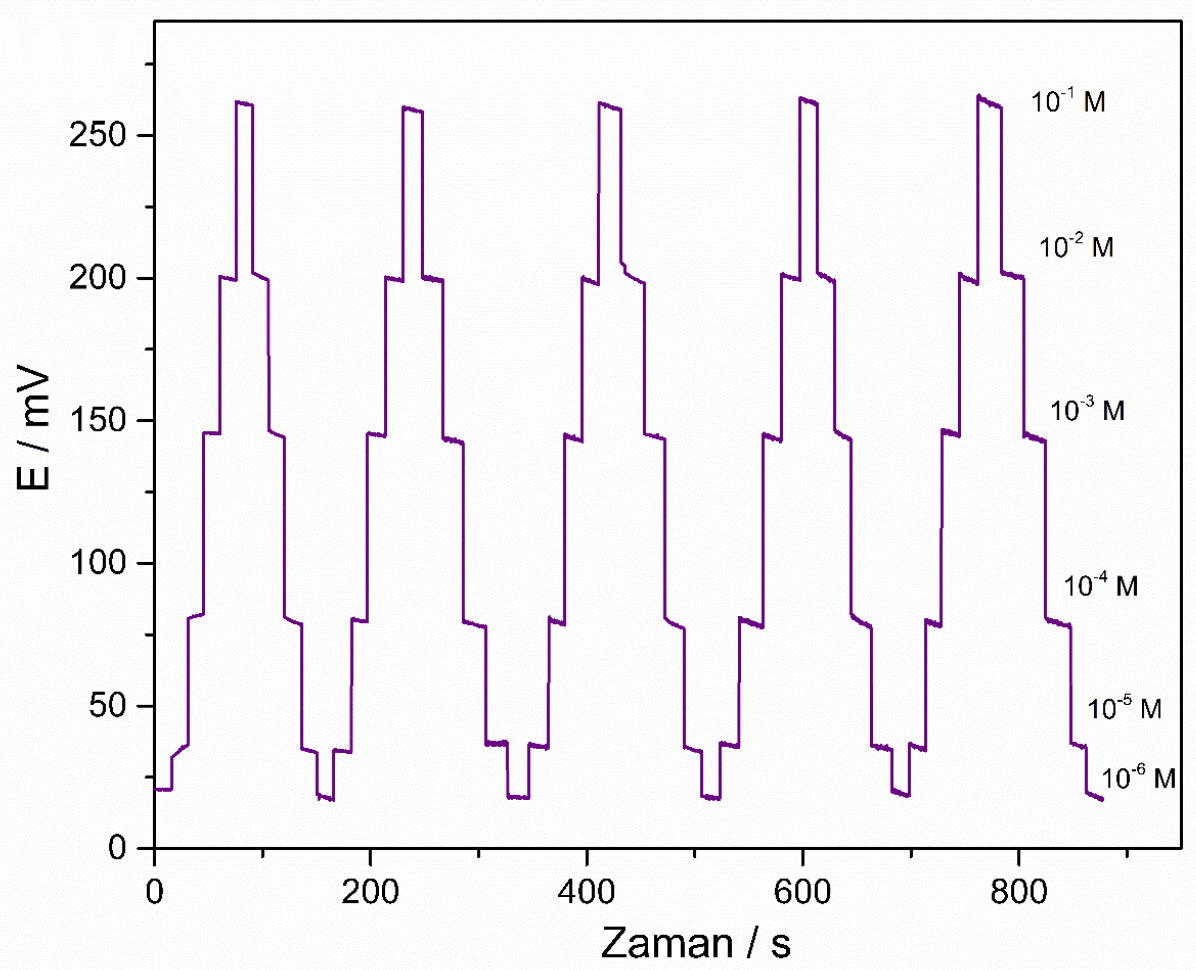

Şekil 6. KR-seçici mikrosensörün tekrarlanabilirliği için potansiyel-zaman grafiği.

Tablo 2. KR-seçici mikrosensöre ait tekrarlanabilirlik potansiyel değerleri.

\begin{tabular}{ccccccc}
\hline \multirow{2}{*}{$\begin{array}{c}\text { Derişim } \\
(\mathrm{mol} / \mathrm{L})\end{array}$} & \multicolumn{5}{c}{ Tekrarlanan Potansiyometrik Ölçümler $(\mathrm{mV})$} & $(\overline{\mathrm{X}} \pm \mathrm{S})^{*}$ \\
\cline { 2 - 7 } & 1 & 2 & 3 & 4 & 5 & \\
\hline $10^{-1}$ & 260,7 & 258,1 & 258,9 & 261,4 & 259,7 & $259,7 \pm 1,3$ \\
$10^{-2}$ & 199,3 & 198,9 & 197,7 & 199,3 & 198,3 & $198,7 \pm 0,7$ \\
$10^{-3}$ & 145,4 & 144,4 & 142,9 & 142,9 & 144,3 & $143,9 \pm 1,1$ \\
$10^{-4}$ & 81,6 & 79,6 & 78,3 & 77,4 & 77,6 & $78,9 \pm 1,7$ \\
$10^{-5}$ & 35,6 & 34,0 & 34,7 & 35,6 & 34,5 & $34,9 \pm 0,7$ \\
$10^{-6}$ & 20,6 & 17,9 & 17,7 & 17,0 & 18,9 & $18,4 \pm 1,4$ \\
\hline
\end{tabular}

$*_{n}=5$ için ortalama değer \pm standart sapması ile birlikte verilmiştir.

KR-seçici mikrosensörün kullanım ömrünü belirlemek için belirli günlerde $10^{-1}-10^{-6}$ mol.L $\mathrm{L}^{-1}$ kreatinin konsantrasyonu aralığındaki standart çözeltiler için potansiyometrik ölçümler alındı ve 
kalibrasyon eğrilerinden eğim değerleri belirlendi. Elde edilen eğim değerleri Şekil 7'de gösterilmiştir. Şekil 7'den de görülebileceği gibi, özellikle 42 gün sonra, eğim değerlerinde belirgin bir azalma görülmüş ve bu durumun sensörün kararlılığının bozulmaya başladığının bir göstergesi olduğu sonucuna varılmıştır. Bu nedenle, sensörün kullanım ömrü yaklaşık 6 hafta olarak tespit edilmiştir.

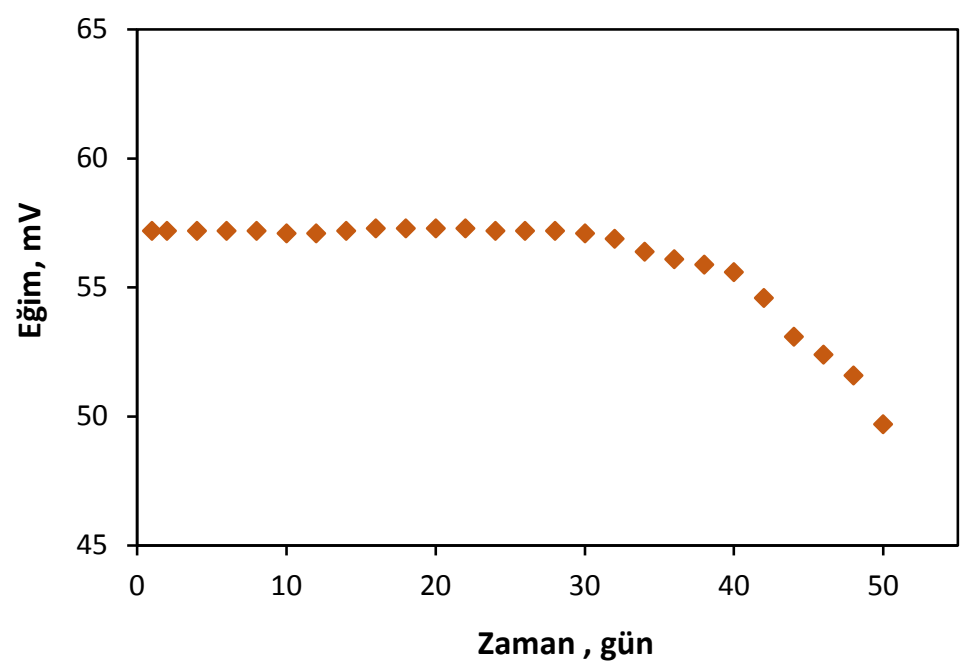

Şekil 7. KR-seçici mikrosensöre ait kararlılık grafiği.

\section{4. pH Etkisi}

Sensör yanıtı üzerine $\mathrm{pH}$ etkisini incelemek için $\mathrm{pH} 3,0-11,0$ aralığında ve herbiri $1,0 \times 10^{-3}$ mol.L $\mathrm{L}^{-1}$ kreatinin içeren çözeltilerde potansiyometrik ölçümler alındı (Şekil 8.).

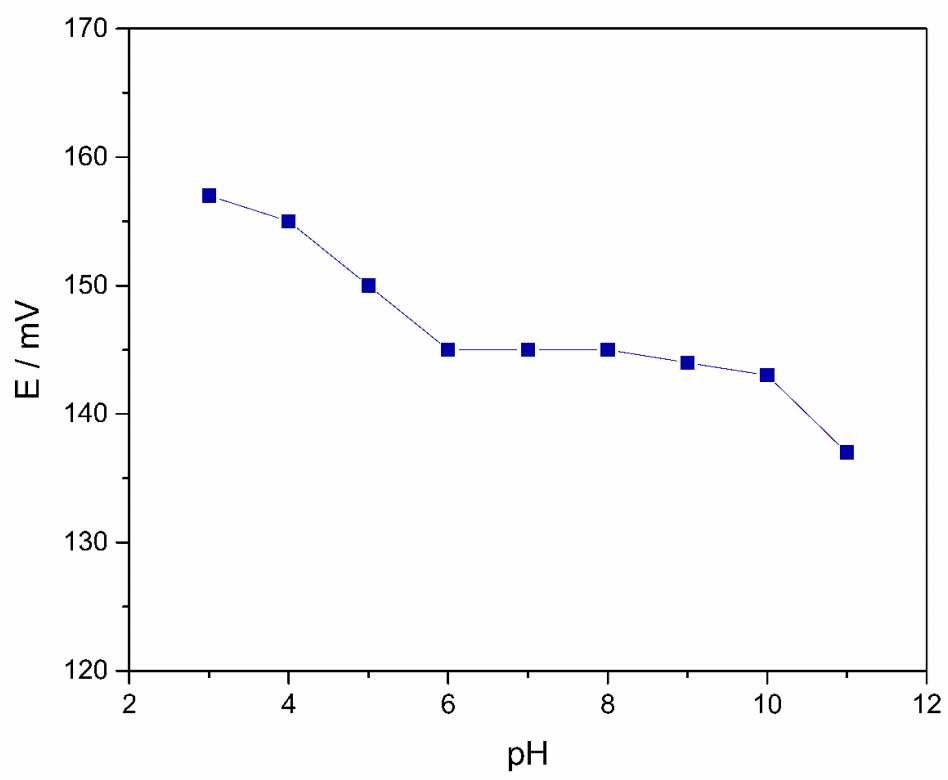

Şekil 8. KR-seçici mikrosensörün pH’ya karşı davranışı. 
Şekil 8'den de görüldüğü gibi, sensör potansiyeli pH: 6,0-10,0 aralığında önemli ölçüde değişmeden kalmıştır. pH: 6,0'dan daha düşük değerlerde potansiyeldeki artış, hidronyum iyonlarının sensör membranında etkileşim yaparak girişime neden olması ile açıklanabilir. Benzer şekilde pH:10,0'dan yüksek değerlerde potansiyeldeki azalma ise hidroksil iyonlarının girişimi ile açıklanabilir. Bu nedenle, geliştirilen sensör için $\mathrm{pH}$ : 6,0-10,0 aralığı optimum $\mathrm{pH}$ çalışma aralığ olarak belirlenmiştir.

\subsection{Seçicilik}

Geliştirilen KR-seçici mikrosensörün kreatinin yanında girişimi muhtemel olabilecek bazı iyonik türlere karşı seçiciliği ayrı çözelti metoduna (Buck ve Lindner, 1994) göre belirlenmiş ve seçicilik katsayıları (log K) aşağıda verilen Nicolsky eşitliği yardımıyla hesaplanmıştır.

$$
\mathrm{K}_{\mathrm{A}, \mathrm{B}}^{\mathrm{pot}}=\frac{a_{\mathrm{A}}}{a_{\mathrm{B}}^{\mathrm{z}_{\mathrm{A}} / \mathrm{z}_{\mathrm{B}}}}
$$

Burada A ve B sırasıyla ana ve girişim yapan türleri; $a$ ilgili türün sensöre karşı cevabını ve z ilgili türün yükünü ifade etmektedir. Hesaplanan seçicilik katsayıları logaritmik olarak Tablo 3 'te verilmiştir. Bilindiği üzere seçicilik katsayısının logaritmik değeri sıfırdan uzaklaştıkça sensörün daha seçici olduğunu ifade edilmektedir. Dolayısıyla değerler incelendiğinde; sensörün birçok tür yanında kreatinine karşı seçici davrandığı ve bunun yanında en çok ve en az girişim yapan türlerin sirasıyla laktoz ve tiyoasetamid olduğu söylenebilir.

Tablo 3. KR-seçici mikrosensör için hesaplanan logaritmik seçicilik katsayıları.

\begin{tabular}{cccc}
\hline Tür & $\log \mathrm{K}_{\mathrm{A}, \mathrm{B}}$ & $\mathrm{Tür}$ & $\log \mathrm{K}_{\mathrm{A}, \mathrm{B}}$ \\
\hline $\mathrm{K}^{+}$ & $-2,04$ & $\mathrm{Zn}^{2+}$ & $-2,91$ \\
$\mathrm{Na}^{+}$ & $-2,00$ & $\mathrm{Ba}^{2+}$ & $-2,95$ \\
$\mathrm{NH}_{4}^{+}$ & $-2,87$ & $\mathrm{Ni}^{2+}$ & $-2,29$ \\
$\mathrm{Ca}^{2+}$ & $-2,20$ & $\mathrm{Co}^{2+}$ & $-2,33$ \\
$\mathrm{Mg}^{2+}$ & $-2,04$ & $\mathrm{Fe}^{3+}$ & $-1,95$ \\
$\mathrm{Cu}^{2+}$ & $-3,54$ & $\mathrm{~Pb}^{2+}$ & $-3,05$ \\
$\mathrm{Cd}^{2+}$ & $-2,83$ & Dopamin & $-2,08$ \\
Fruktoz & $-3,54$ & Glukoz & $-2,00$ \\
Üre & $-2,08$ & Laktoz & $-1,12$ \\
Trietanolamin & $-2,12$ & Tiyoüre & $-2,58$ \\
Askorbik asit & $-1,83$ & Tiyoasetamid & $-3,62$ \\
\hline
\end{tabular}

A: Kreatinin, B: Girişim yapan tür 


\subsection{Sıcaklık Çalışma Aralığı}

Sıcaklık, iyon-seçici elektrotların performansına etki eden diğer önemli bir parametredir. Geliştirilen sensörün optimum çalışma sıcaklık aralığını belirlemek için $10^{-2}$ mol.L ${ }^{-1} \mathrm{KR}$ çözeltisinin sıcaklığı $5^{\circ} C^{\prime}$ den $70{ }^{\circ} C^{\prime}$ ye değiştirildi ve ölçümler alındı ( Şekil 9). Şekil 9'dan da görüleceği gibi; KR-seçici mikrosensörün, yaklaşı $10-35{ }^{\circ} \mathrm{C}$ sicaklık aralığında ( \pm 2 mV'luk sapma ile) performansında önemli bir değişiklik olmadan çalışabildiği ve yaklaşık $35^{\circ} \mathrm{C}$ 'nin üzerinde ise sensör performansının sıcaklık değişiminden etkilendiği tespit edildi. Ayrıca sensörün $35{ }^{\circ} \mathrm{C}$ 'nin üzerinde deforme olduğu belirlendi (Dybko, 2001).

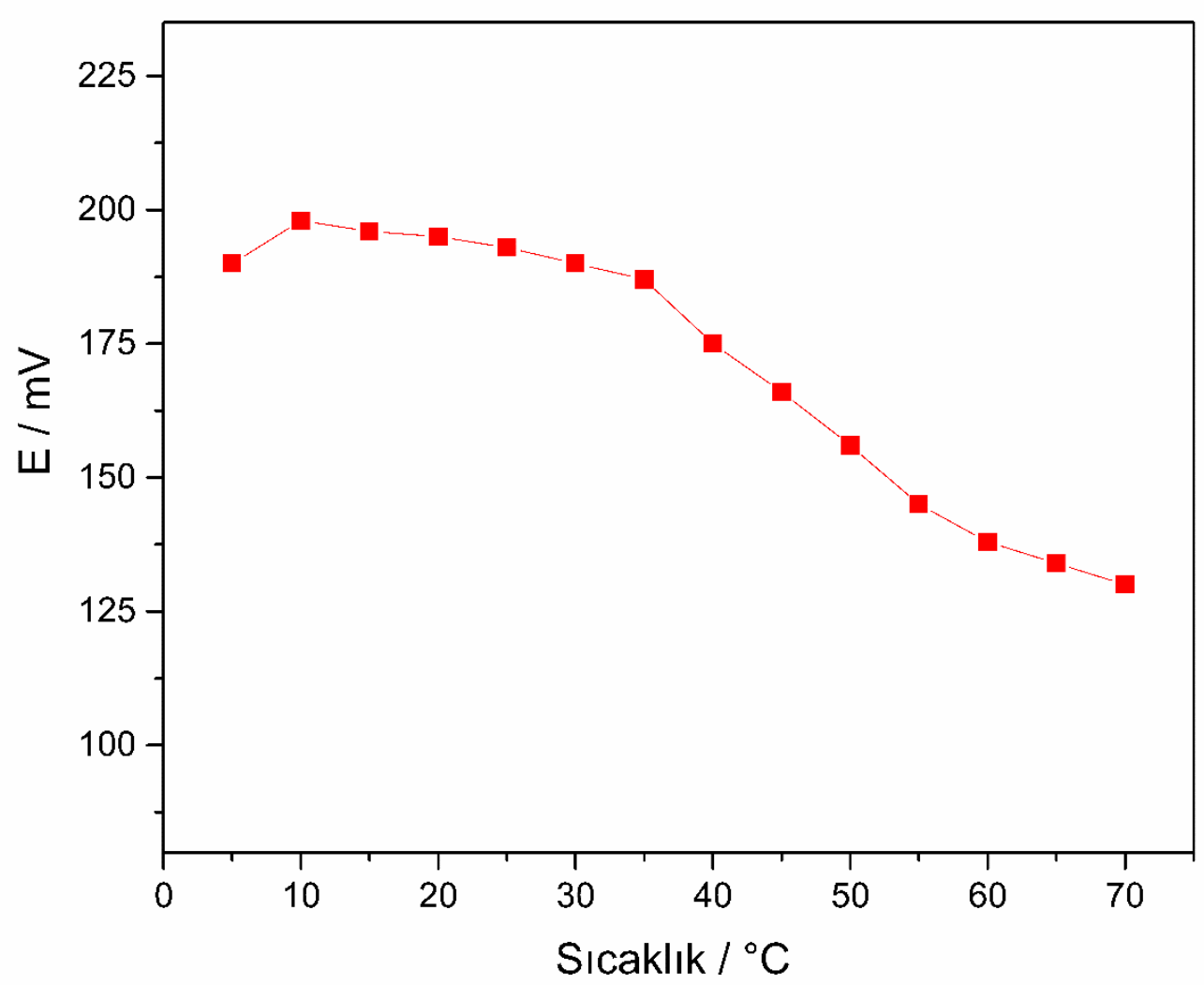

Şekil 9. KR-seçici mikrosensör performansına sıcaklığın etkisi.

\subsection{Kreatinin-Seçici Sensörlerin Karşılaştırılması}

Geliştirilen mikrosensörün literatürde verilen kreatinin-seçici mikrosensörlerle performans karşılaştırması Tablo 4'te verilmiştir. Geliştirilen sensörün çoğu durumda daha önce bildirilen sensörlerle kıyaslanabilir olduğu düşünülmektedir. Geliştirilen sensör, hızlı cevap, düşük tayin limiti, geniş doğrusal aralık ve düşük maliyet gibi avantajlara sahiptir. Bu nedenle geliştirilen sensörün, kreatinin seçici sensörler listesinde iyi bir örnek olarak kabul göreceği düşünülmektedir. 
Tablo 4. Geliştirilen sensörün bildirilen çeşitli kreatinin-seçici sensörlerle karşılaştırılması.

\begin{tabular}{cccccccc}
\hline $\begin{array}{c}\text { Eğim, } \\
\mathrm{mV}\end{array}$ & $\begin{array}{c}\text { Doğrusal aralık, } \\
\mathrm{mol} / \mathrm{L}\end{array}$ & $\begin{array}{c}\text { Cevap } \\
\text { zamanı, s s }\end{array}$ & $\begin{array}{c}\text { Kullanım } \\
\text { ömrü, hafta }\end{array}$ & $\begin{array}{c}\mathrm{pH} \\
\text { aralığ1 }\end{array}$ & $\begin{array}{c}\text { Tayin limiti, } \\
\mathrm{mol} / \mathrm{L}\end{array}$ & Girişim & Kaynak \\
\hline 59,5 & $1 \times 10^{-1}-1 \times 10^{-5}$ & 6 & 24 & $3,5-6,5$ & $1,0 \times 10^{-5}$ & - & Elmosallamy., 2006 \\
27,5 & $1 \times 10^{-1}-8 \times 10^{-5}$ & $<10$ & 6 & 7,2 & $6,0 \times 10^{-5}$ & - & Cubuk ve ark., 2012 \\
23,2 & $1 \times 10^{-3}-1 \times 10^{-6}$ & $91-192$ & - & - & $5,5 \times 10^{-6}$ & üre & Darmokoesoem ve ark., 2017 \\
28,4 & $1 \times 10^{-3}-1 \times 10^{-6}$ & $91-192$ & - & - & $5,5 \times 10^{-6}$ & üre & Darmokoesoem ve ark., 2017 \\
52,0 & $1 \times 10^{-5}-1 \times 10^{-7}$ & $<50$ & 7 & 7,0 & $7,9 \times 10^{-8}$ & & Khasanah ve ark., 2018 \\
- & $1 \times 10^{-5}-1 \times 10^{-2}$ & - & - & 3,8 & $1,0 \times 10^{-5}$ & - & Erenas ve ark., 2019 \\
57,2 & $1 \times 10^{-1}-1 \times 10^{-5}$ & $<15$ & 6 & $6-10$ & $5,0 \times 10^{-6}$ & laktoz & Bu çalışma \\
\hline
\end{tabular}

\subsection{Analitik Uygulama}

Kreatinin içeren sentetik numunelerdeki kreatinin miktarı, KR-seçici mikrosensör ile belirlenmeye çalışıldı. İlk önce doğrudan ölçüm yöntemi kullanılarak potansiyometrik kreatinin tayini gerçekleştirildi. Ardından UV-Vis analizi için $200 \mathrm{~nm}$ dalga boyunda spektroskopik ölçümler alındı ve sonuçlar hesaplandı. Her iki metotla elde edilen sonuçlar için istatistiksel hesaplamalar yapıldı (Tablo 5). Elde edilen sonuçlara istatistiksel çift taraflı $t$-testi uygulandı (Skoog ve ark., 2004). Hesaplanan deneysel $t$ değerinin $(1,88) \% 95$ güven seviyesinde ve serbestlik derecesi 7 için tablo değeri olan kritik $t$ değerinden $(2,36)$ küçük olması, her iki metot ile elde edilen veriler arasında önemli derecede farklılıkların olmadığı sonucunu desteklemektedir.

Tablo 5. Sentetik kreatinin çözeltileri için potansiyometri ve UV-Vis sonuçları, \% bağıl hatalar ve $t$ değeri.

\begin{tabular}{|c|c|c|c|c|c|c|}
\hline \multirow{2}{*}{ No } & \multicolumn{3}{|c|}{ KR miktarı, ppm } & \multirow[b]{2}{*}{$\mathbf{E}_{\mathbf{r}}{ }^{a}$} & \multirow[b]{2}{*}{$\mathbf{E}_{\mathbf{r}}{ }^{b}$} & \multirow[b]{2}{*}{$t^{\mathrm{c}}$} \\
\hline & Standart & Potansiyometri & UV-Vis & & & \\
\hline 1 & 1,13 & $1,10 \pm 0,03$ & $1,11 \pm 0,01$ & $-2,42$ & $-1,48$ & \multirow{8}{*}{1,88} \\
\hline 2 & 2,83 & $2,76 \pm 0,06$ & $2,78 \pm 0,02$ & $-2,66$ & $-1,79$ & \\
\hline 3 & 5,66 & $5,50 \pm 0,16$ & $5,56 \pm 0,14$ & $-2,84$ & $-1,81$ & \\
\hline 4 & 11,31 & $10,92 \pm 0,78$ & $11,06 \pm 0,50$ & $-3,43$ & $-2,25$ & \\
\hline 5 & 28,28 & $24,55 \pm 2,02$ & $27,36 \pm 1,09$ & $-3,25$ & $-3,47$ & \\
\hline 6 & 56,56 & $51,57 \pm 4,88$ & $53,92 \pm 3,58$ & $-7,95$ & $-4,67$ & \\
\hline 7 & 113,12 & $104,94 \pm 5,37$ & $107,39 \pm 2,68$ & $-7,23$ & $-5,07$ & \\
\hline 8 & 282,80 & $259,73 \pm 17,34$ & $269,58 \pm 4,79$ & $-8,16$ & $-5,03$ & \\
\hline
\end{tabular}

${ }^{\mathrm{a}}$ : Potansiyometrik veriler için hesaplanan \% bağıl hata değerleridir.

b : Spektroskopik veriler için hesaplanan \% bağıl hata değerleridir.

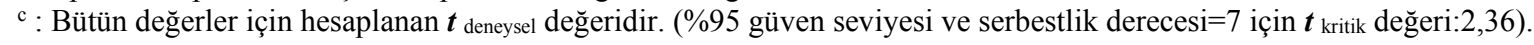




\section{Sonuçlar ve Öneriler}

Bu çalışmada, kreatinin baskılanmış polimer temelli tümüyle katı-hal PVC-membran KR-seçici potansiyometrik mikrosensör geliştirilmiştir. Geliştirilen sensörün; $10^{-1}-10^{-5}$ mol.L ${ }^{-1}$ konsantrasyon aralığında 57,2 $\pm 1,2 \mathrm{mV}$ 'luk eğim değeri ile Nernst davranışına yakın cevap sergilediği, tayin sınırının $5,0 \times 10^{-6}$ mol.L ${ }^{-1}$, kullanım ömrünün yaklaşık 6 hafta, cevap süresinin 15 s'den kısa ve pH çalışma aralığının 6,0-10,0 olduğu belirlendi. Mikrosensör aynı zamanda sentetik örneklerde bulunan kreatininin hızlı, doğru, seçici ve tekrarlanabilir tespiti için başarıyla kullanıldı. Geliştirilen mikrosensörün diğer türler yanında KR'ne karşı seçici davrandığı tespit edildi.

Geliştirilen KR-seçici mikrosensörün performansı, literatürde yer alan bazı KR-seçici sensörler ile bazı potansiyometrik özellikler açısından karşılaştırıldığında; önerilen sensörün literatürde verilen KR-seçici sensörlere göre bazı avantajlara sahip olduğu belirlendi. Geliştirilen sensör, geniş çalışma aralığı, düşük tayin sınırı, basit kullanım, düşük maliyet ve hızlı cevap süresine sahip olup, minyatür uçlu ve katı hal tipinde olması sebebiyle küçük hacimli numune analizinde kolayca kullanılabilir. Geliştirilen KR-seçici mikrosensör, literatürdeki KR-seçici sensörler arasında başarıyla yer alabilecek kapasitededir. Ayrıca geliştirilen mikrosensörün ileriki çalışmalarda akış enjeksiyon analizi gibi kromatografik sistemlerde dedektör olarak başarıyla kullanılabileceği düşünülmektedir.

\section{Teşekkür}

Yazarlar, Giresun Üniversitesi Bilimsel Araştırma Projeleri Komisyonu Başkanlı̆̆ı'nın desteğine (proje no: FEN-BAP-C-281119-81) teşekkür eder.

\section{Yazarların Katkısı}

Tüm yazarlar çalışmaya eşit katkıda bulunmuştur.

\section{Çıkar Çatışması Beyanı}

Yazarlar arasında herhangi bir çıkar çatışması bulunmamaktadır.

\section{Araştırma ve Yayın Etiği Beyanı}

Yapılan çalışmada araştırma ve yayın etiğine uyulmuştur. 


\section{Kaynaklar}

Barnea, Z. H. and Abookasis, D. (2019). Determination of creatinine level in patient blood samples by Fourier NIR spectroscopy and multivariate analysis in comparison with biochemical assay. Journal of Innovative Optical Health Sciences, 12(6), 1950015.

Borisov, S. M., Mayr T., Mistlberger, G., Waich, K., Koren, K. Chojnacki, P. and Klimant, I. (2019). Precipitation as a simple and versatile method for preparation of optical nanochemosensors, Talanta, 79(5), 1322-1330.

Buck, R. P. and Lindner E. (1994). IUPAC Analytical Chemistry Division, Commission on Electroanalytical Chemistry, Recomendations for nomen-clature of Ion-selective Electrodes, Pure and Applied Chemistry, 66, 2527-2536.

Carducci, C., Birarelli M. Leuzzi, V., Carducci, C., Battini R., Cioni G. and Antonozzi I., (2002). Guanidinoacetate and creatine plus creatinine assessment in physiologic fluids: an effective diagnostic tool for the biochemical diagnosis of arginine: glycine amidinotransferase and guanidinoacetate methyltransferase deficiencies. Clinical Chemistry, 48(10), 1772-1778.

Chen, L., Xu, S., and Li, J., (2011). Recent advances in molecular imprinting technology: current status, challenges and highlighted applications. Chemical Society Reviews, 40, 2922-2942.

Cheong W. J., Yang S. H. and Ali F. (2013). Molecular imprinted polymers for separation science: a review of reviews. Journal of Separation Science, 36(3), 609-628.

Cubuk O., Altikatoglu M., Erci V., Isildak I., and Tinkilic N. (2012). An all solid-state creatinine biosensor based on ammonium-selective PVC-NH ${ }_{2}$ membrane electrode. Sensor Letters, 10, 1-6.

Darmokoesoemo H., Khasanah M., Sari N. M., Kadmi Y., Elmsellem H., Kusuma H. S. (2017). Development of electrode carbon paste modified by molecularly imprinted polymer as sensor for analysis of creatinine by potentiometric. Results in Physics, 7, 1808-1817.

Darmokoesoemo H., Khasanah M., Sari N. M. and Kusuma H.S. (2017). Analysis of creatinine by potentiometric using electrode carbon paste modified by molecularly imprinted polymer as sensor. Rasayan Journal of Chemistry, 10(2), 450-453.

Davis, C. P., Shiel C. W. (2021, January 29). Creatinine (Low, High, Blood Test Results Explained). Retrieved from https://www.medicinenet.com/creatinine blood test/article.htm

Delaney T.P., Mirsky V.M. and Wolfbeis O.S., (2002). Capacitive creatinine sensor based on a photografted molecularly imprinted polymer. Electroanalysis, 14(3), 221-224.

Dybko A. (2001). Errors in Chemical Sensor Measurements. Sensors, (1), 29-37.

Elmosallamy M.A.F. (2006). New potentiometric sensors for creatinine. Analytica Chimica Acta, 564(2), 253257.

Erenas M. M., Ortiz-Gómez I., Orbe-Payá I., Hernández-Alonso D., Ballester P., Blondeau P., Andrade F. J., Salinas-Castillo A. and Capitán-Vallvey L. F. (2019). Ionophore-based optical sensor for urine creatinine determination. ACS Sensors, 4, 421-426.

Ge S., Yan M., Cheng X., Zhang C., Yu J., Zhao P. and Gao W. (2010). On-line molecular imprinted solidphase extraction flow-injection fluorescence sensor for determination of florfenicol in animal tissues. Journal of Pharmaceutical and Biomedical Analysis, 52(4), 615-619.

Horne M.M. and Swearingen P. L. (1993). Fluids, Electrolytes and Acid-Base Balance. (2nd ed.). Mosby, St Louis.

Hu J., Dai H., Zeng Y., Yang Y., Wang H., Zhu X., Li L., Zhou G., Chen R. and Guo L. (2019). A crosslinker-based poly(ionic liquid) for sensitive electrochemical detection of 4-nonylphenol. Nanomaterials, 9(4), 513.

Isildak I. and Covington A. K. (1993). Ion-selective electrode potentiometric detection in ion-chromatography. Electroanalysis, 5 (9-10), 815-824.

Isildak, I.; Yolcu M.; Isildak O., Demirel N., Topal G. and Hosgoren H. (2004). All-solid-state PVC membrane Ag+-selective electrodes based on diaza-18-crown-6 compounds, Microchimica Acta, 144(1), 177-181.

Khasanah M., Handajani U. S., Widati A. A., Abdulloh A. and Rindarti R. R. (2018). Construction and performance of creatinine selective electrode based on carbon paste-imprinting zeolite. Analytical \&Bioanalytical Electrochemistry. 10(4), 429-438.

Kintzel, P. E. (2001). Anticancer drug-induced kidney disorders incidence, prevention and management. Drug Safety, 24(1), 19-38.

Kryscio D. R. and Peppas N. A., (2012). Critical review and perspective of macromolecularly imprinted polymers. Acta Biomaterialia, 8(2), 461-473. 
Mohammadi S. and Khayatian G. (2015). Highly selective and sensitive photometric creatinine assay using silver nanoparticles. Microchimica Acta, 182:1379-1386.

Royani I., Widayani, Abdullah M. and Khairurrijal (2014). An atrazine molecularly imprinted polymer synthesized using a cooling-heating method with repeated washing: Its physico-chemical characteristics and enhanced cavities. International Journal of Electrochemical Science, 9, 5651-5662.

Salgarello M., Visconti G. and Barone-Adesi L. (2013). Interlocking circumareolar suture with undyed polyamide thread: a personal experience, Aesthetic Plastic Surgery, 37(5), 1061-1062.

Sellergren B. and Lanza F., (2001). Molecularly Imprinted Polymers: Man-made mimics of antibodies and their application in analytical chemistry: Techniques and instrumentation in analytical chemistry, Amsterdam, Netherlands: Elsevier Science.

Sukhang M., Junkuy A., Buckley N., Mohamed F. and Wunnapuk K. (2020). An LC-MS/MS method for creatine and creatinine analysis in paraquat-intoxicated patients. Journal of Environmental Science and Health, Part B, 55(3), 273-282.

Tsikas D., Wolf A., Mitschke A., Gutzki F-M., Will W. and Bader M. (2010). GC-MS determination of creatinine in human biological fluids as pentafluorobenzyl derivative in clinical studies and biomonitoring: Inter-laboratory comparison in urine with Jaffé, HPLC and enzymatic assays. Journal of Chromatography B: Analytical Technologies in the Biomedical and Life Sciences, 1;878(27), 25822592.

Vitali L., Gonçalves S., Rodrigues V., Fávere V. T. and Micke G. A. (2017). Development of a fast method for simultaneous determination of hippuric acid, mandelic acid, and creatinine in urine by capillary zone electrophoresis using polymer multilayer-coated capillary. Analytical and Bioanalytical Chemistry, 409(7), 1943-1950.

Wanga Y., Zhang Z., Jain V., Yi J., Mueller S., Sokolov J., Liu Z., Levon K., Rigas B. and Rafailovich M. H. (2010). Potentiometric sensors based on surface molecular imprinting: detection of cancer biomarkers and viruses, Sensors and Actuators B: Chemical, 146(1), 381-387.

Wyss, M. and Kaddurah-Daouk, R., (2000). Creatine and creatinine metabolism. Physiological Reviews, 80(3), 1107-1213.

Yolcu M. and Dere N. (2018). All-solid-state potentiometric Cu(II)-selective sensor based on ion imprinted methacrylamide polymer, Electroanalysis, 30, 1147-1154. 